University of South Carolina

Scholar Commons

$11-1994$

\title{
Descriptive Epidemiology of Physical Activity in Adolescents
}

Russell R. Pate

University of South Carolina - Columbia, rpate@mailbox.sc.edu

Barbara J. Long

Gregory W. Heath

Follow this and additional works at: https://scholarcommons.sc.edu/

sph_physical_activity_public_health_facpub

Part of the Public Health Commons

\section{Publication Info}

Published in Pediatric Exercise Science, Volume 6, Issue 4, 1994, pages 434-447.

Pate, R. R., Long, B. J., Heath, G. (1994). Descriptive epidemiology of physical activity in adolescents.

Pediatric Exercise Science, 6(4), 434-447.

(C) Pediatric Exercise Science, 1994, Human Kinetics

This Article is brought to you by the Physical Activity and Public Health at Scholar Commons. It has been accepted for inclusion in Faculty Publications by an authorized administrator of Scholar Commons. For more information, please contact digres@mailbox.sc.edu. 


\title{
Descriptive Epidemiology of Physical Activity in Adolescents
}

\author{
Russell R. Pate, Barbara J. Long, and Greg Heath
}

\begin{abstract}
This paper reviews the descriptive epidemiology of physical activity in adolescents. Large population-based studies were reviewed, along with smaller studies using objective monitoring of physical activity. Estimates showed that adolescents engage in physical activity of any intensity for a mean of one hour per day. Approximately two thirds of males and one quarter of females participate in moderate to vigorous activity for $20 \mathrm{~min} 3$ or more days per week. Activity levels decline with increasing age across adolescence, and this decrease is more marked in females than in males. Comparison of these data to physical activity guidelines for adolescents suggests the vast majority are meeting the guideline of accumulating physical activity. However, a substantial number of males, and the majority of females, are not meeting the guideline for moderate to vigorous physical activity.
\end{abstract}

Regular participation in moderate and/or vigorous physical activity is an acknowledged component of a healthy lifestyle. Among adults, physical inactivity is a risk factor for several chronic diseases, including coronary heart disease, hypertension, obesity, diabetes, and certain cancers (1). Surveys show that physical inactivity is highly prevalent among adults in all sociodemographic categories (2). Accordingly, there is broad consensus that promotion of physical activity during adulthood should be a priority in efforts to enhance the public's health (3).

There is also general agreement that the physical activity behavior of children and youth is an important health issue (4). However, the relationship between physical activity and health is not as well understood in youngsters as it is in adults (5). Perhaps for this reason, somewhat divergent viewpoints have been expressed concerning the status of physical activity behavior in youth. Some have taken the position that today's youth are not as active as is required for good health and fitness (6), and that emphasis should be given to increasing habitual activity in youth. Others have concluded that youth, at least by comparison with older age groups, are quite physically active, and consequently, activity

Russell R. Pate is with the Dept. of Exercise Science, School of Public Health at the University of South Carolina, Columbia, SC 29208. Barbara J. Long is with Project PACE at San Diego State University, San Diego, CA 92182. Greg Heath is with the Epidemiology Program Office, 1600 Clifton Rd., N.E., Centers for Disease Control, Atlanta, GA 30333. 
programs for youth should be focused on the long-term goal of promoting adult physical activity (7).

Clearly, there is a need to establish, at least on a tentative basis, a physical activity standard for youth. Such a standard is needed so the prevalence of this behavior (or its absence) can be determined and so intervention programs can be designed coherently. In attempting to establish an activity standard, one needs to understand the current physical activity behavior of adolescent youth. Accordingly, this paper summarizes current knowledge of the physical activity behavior of youth. An epidemiologic perspective is taken, and emphasis is given to studies that have described physical activity behavior in defined populations. However, applicable small group studies are summarized as well. The term adolescent is operationally defined as including persons in the 11-21 age range. The primary focus is on youngsters in North America. Attention is given to activity patterns related to age and gender.

\section{Definitions}

Physical activity has been defined as " any bodily movement produced by skeletal muscles that results in energy expenditure" (8, p. 127). Exercise is a specific type of physical activity that has been defined as "planned, structured and repetitive bodily movement done to improve or maintain one or more components of physical fitness"' (8, p. 127). According to these widely accepted definitions, physical activity is a very broad construct that includes almost all kinds of movement, but exercise is a much narrower and more purposeful construct.

Because the health and fitness effects of physical activity are presumed to be independent of the reasons for performance of the activity, this paper focuses on physical activity, not exercise. However, it must be acknowledged that most of the procedures that have been used to measure physical activity in adolescents have focused on specific activities that might be best described as modes of exercise.

\section{Sources of Information}

Given the long-standing concerns about the physical activity habits of adolescent youth, there are surprisingly few published studies describing physical activity behavior in adolescents. The pertinent studies can be grouped into two categories based on the types of instruments that were used to measure physical activity behavior. Most common are the studies in which self-report instruments were used, and some of these investigations were population-based surveys (9). In the U.S., two such surveys have been conducted during the past decade. The National Children and Youth Fitness Study, Phase I (NCYFS-I) was undertaken in the mid-1980s (10). In that study, physical fitness and physical activity habits were measured in a nationally representative sample of 10- to 18-year-olds. Physical activity was measured using a detailed instrument with which the subject reported, on a seasonal basis, typical weekly frequency and duration of participation in up to 10 self-selected modes of physical activity.

More recently, the Youth Risk Behavior Survey (YRBS) was initiated under the auspices of the U.S. Centers for Disease Control and Prevention, and 
the YRBS questionnaire includes several items pertinent to physical activity behavior (11). YRBS was first administered to large numbers of American high school students in 1990, and the data collected in that survey will be summarized in this paper. It is important to note that the physical activity questions in YRBS are designed to assess recent frequency of participation in bouts of moderate and vigorous physical activity. This methodology is quite different from that used in NCYFS-I. Population-based surveys of physical activity behavior have been conducted in England and Canada using methods somewhat similar to those of YRBS, and the results of these studies will be summarized.

The second major methodology used to study physical activity behavior in youth involves objective monitoring of activity with motion sensors or heart rate monitors (12). Because these methods are burdensome and expensive, they have not been used in population-based studies. Nonetheless, several of these studies will be summarized here because their results can be used as a crossreference to "validate" the findings of the population-based self-report studies.

\section{How Active Are Adolescents?}

\section{Population Surveys}

The most detailed information on the physical activity habits of U.S. adolescents comes from NCYFS-I. Table 1 presents a summary of the results of NCYFS-I. This summary was abstracted from the published report of the results of the NCYFS-I (13), but some modifications were made so that total weekly physical activity time could be estimated. A key modification was applied to the estimate of physical activity time in physical education. The published data were based on a determination of the weekly time in which the youngster could have been active in physical education (frequency of class meetings $\times$ [duration of class period - time for changing and showering]). Because it is known that most youngsters are not physically active most of the time in physical education (14), we opted to estimate activity time in physical education as one third of the available time. This is probably a generous estimate.

As indicated in Table 1, NCYFS-I found that adolescents reported participating in an average of 1.8 hours of physical activity per day in situations outside of physical education. Only group means were presented in the published report; however, additional analyses of the NCYFS-I data set reveal that the standard deviations approximate $50-60 \%$ of the means. Thus, there appears to be considerable variability in the physical activity habits of U.S. adolescents.

Although the published report did not present detailed information on physical activity time in physical education, the NCYFS-I data set does allow derivation of an estimate of this potentially important component of a youngster's physical activity profile. All the figures presented in Table 1 are rounded and estimated from previously published information and from unpublished analyses. NCYFS-I and other studies have shown that the percentage of students enrolled in physical education decreases with age, although for those enrolled, physical education class time increases. The net effect is that mean time in physical education (averaged across all students) remains in the range of 100-150 minutes per week. Assuming that about one third of this time is actually dedicated to 
physical activity, weekly physical activity time in physical education can be estimated at 30-50 minutes (0.08-0.12 hours per day).

Table 1 presents the estimated total physical activity times for boys and girls surveyed in NCYFS-I. The figures fall in the range of 1.7-2.0 hours per day and are calculated as the sum of the physical education and outside physical education activity times. It is not possible to formally calculate variability estimates, but standard deviations would be expected to fall in the range of $0.8-1.0$ hours per day. Accordingly, the results of NCYFS-I indicate that, on average, U.S. adolescents engage in 1.5-2.0 hours of physical activity per day. It seems clear that there is a considerable variability around this mean, and it is likely that the data are skewed by very high activity levels in a small percentage of youngsters.

None of the other population surveys of physical activity behavior in adolescents have used instruments that allow direct comparisons with the findings of NCYFS-I. Most of the other surveys, including YRBS, have used a question or series of questions that were designed to quantify activity on the basis of sessions of activity per week or days per week on which physical activity sessions were performed. Table 1 summarizes the results of the YRBS study completed in 1990. These results indicate that only about half of boys and one quarter of girls participate in vigorous exercise sessions 3 or more days per week. When the frequency of participation in moderate intensity activity is combined with participation in vigorous exercise, about two thirds of boys and half of girls reported exercising at a frequency of three or more sessions per week. About one third of both boys and girls reported participating frequently in vigorous exercise sessions in physical education classes.

The results of the recent National Fitness Survey in England (15) can be compared to those of YRBS in the U.S. As demonstrated in Table 1, about two thirds of males and half of females in the 16-24 age group reported participating in 12 or more moderate and/or vigorous exercise sessions during the preceding month. This prevalence of regular participation in moderate and/or vigorous physical activity is quite similar to that found in the U.S. with YRBS, though it should be noted that the age ranges for participants in these two surveys is somewhat different.

Survey data from Canada, reported by Stephens (16) and summarized in Table 1 , found the prevalence of participation in vigorous aerobic activity at a frequency of three or more days per week to be $74 \%$ for adolescent males and $67 \%$ for adolescent females. While methodological differences should be noted, these data suggest that regular participation in vigorous physical activity is more prevalent among Canadian adolescents than among those in the U.S. or England.

\section{Small Group Studies}

The available literature includes a small number of studies in which either objective measurement procedures (e.g., heart rate monitors, motion sensors) and/or detailed short-term retrospective physical activity reports have been used with adolescents $(17,18,19,20,21)$. In the present context, these studies are of interest because their results can be used in examining, in an indirect manner, the "validity" of the data derived in the population surveys. 
Table 1 Results of Population Studies of Physical Activity (PA) in Adolescents

\begin{tabular}{|c|c|c|c|c|c|c|c|c|c|}
\hline Study & Sample & Method & $\begin{array}{c}\text { Total } \\
\text { PA time } \\
\text { (hr/day) }\end{array}$ & $\begin{array}{l}\text { PA time } \\
\text { in PE } \\
\text { (hr/day) }\end{array}$ & $\begin{array}{l}\text { PA time } \\
\text { outside PE } \\
\text { (hr/day) }\end{array}$ & $\begin{array}{c}\% \\
\text { Enrolled } \\
\text { in PE }\end{array}$ & $\begin{array}{c}\% \\
\text { Vigorously } \\
\text { active } \\
3 \mathrm{~d} / \mathrm{wk}\end{array}$ & $\begin{array}{c}\% \\
\text { Moderately } \\
\text { active } \\
3 \mathrm{~d} / \mathrm{wk}\end{array}$ & $\begin{array}{c}\% \\
\text { Vig. or mod. } \\
\text { active } \\
3 \mathrm{~d} / \mathrm{wk}\end{array}$ \\
\hline $\begin{array}{l}\text { National } \\
\text { Children and } \\
\text { Youth Fitness } \\
\text { Study (10) } \\
\text { U.S.A. }\end{array}$ & $\begin{array}{l}\text { National } \\
\text { probability } \\
\text { sample; } \\
N=8,800 ; \\
\text { Grade } 5-12 \\
\text { students }\end{array}$ & Questionnaire & $\begin{array}{l}\text { Grade } 5-6: \\
\mathrm{T}=1.9, \\
\mathrm{M}=2.0, \\
\mathrm{~F}=1.7 ; \\
\text { Grade } 7-9: \\
\mathrm{T}=2.0 \\
\mathrm{M}=2.1, \\
\mathrm{~F}=1.9 ; \\
\text { Grade } 10-12: \\
\mathrm{T}=1.8 \\
\mathrm{M}=1.9 \\
\mathrm{~F}=1.8\end{array}$ & $\begin{array}{l}\text { Grade } 5-6: \\
\mathrm{T}=0.08, \\
\mathrm{M}=0.08, \\
\mathrm{~F}=0.08 ; \\
\text { Grade } 7-9: \\
\mathrm{T}=0.12, \\
\mathrm{M}=0.12, \\
\mathrm{~F}=0.12 ; \\
\text { Grade } 10-12: \\
\mathrm{T}=0.08, \\
\mathrm{M}=0.08, \\
\mathrm{~F}=0.08\end{array}$ & $\begin{array}{l}\text { Grade } 5-6: \\
\mathrm{T}=1.8, \\
\mathrm{M}=2.0, \\
\mathrm{~F}=1.6 ; \\
\text { Grade } 7-9: \\
\mathrm{T}=1.9, \\
\mathrm{M}=1.8, \\
\mathrm{~F}=2.0 ; \\
\text { Grade } 10-12: \\
\mathrm{T}=1.7, \\
\mathrm{M}=1.8, \\
\mathrm{~F}=1.7\end{array}$ & $\begin{array}{l}\text { Grade 5-6: } \\
\mathrm{T}=97 \\
\mathrm{M}=97 \\
\mathrm{~F}=97 \\
\text { Grade } 7-9: \\
\mathrm{T}=88, \\
\mathrm{M}=88, \\
\mathrm{~F}=87 \\
\text { Grade } 10-12 \\
\mathrm{~T}=59 \\
\mathrm{M}=62, \\
\mathrm{~F}=56\end{array}$ & & & \\
\hline $\begin{array}{l}\text { Youth Risk } \\
\text { Behavior } \\
\text { Survey (1993) } \\
\text { U.S.A. }\end{array}$ & $\begin{array}{l}\text { National } \\
\text { school } \\
\text { sample; } \\
N= \\
11,631\end{array}$ & Questionnaire & & & & $\begin{array}{l}\text { Grade } 9 \\
\mathrm{~T}=71 \\
\mathrm{M}=76 \\
\mathrm{~F}=67\end{array}$ & $\begin{array}{l}\text { Grade 9: } \\
\mathrm{T}=40 \\
\mathrm{M}=52 \\
\mathrm{~F}=31\end{array}$ & $\begin{array}{l}\text { Grade } 9 \\
\mathrm{~T}=40 \\
\mathrm{M}=47 \\
\mathrm{~F}=13\end{array}$ & $\begin{array}{l}\text { Grade 9: } \\
\mathrm{T}=60 \\
\mathrm{M}=70 \\
\mathrm{~F}=51\end{array}$ \\
\hline
\end{tabular}


Grade 9-12

students

$\begin{array}{llll}\text { Grade 10: } & \text { Grade } 10: & \text { Grade } 10: & \text { Grade 10: } \\ \mathrm{T}=59, & \mathrm{~T}=41, & \mathrm{~T}=39, & \mathrm{~T}=58, \\ \mathrm{M}=64, & \mathrm{M}=55, & \mathrm{M}=46, & \mathrm{M}=69, \\ \mathrm{~F}=54 ; & \mathrm{F}=27 ; & \mathrm{F}=33 ; & \mathrm{F}=48 ; \\ \text { Grade } 11: & \text { Grade } 11: & \text { Grade } 11: & \text { Grade } 11: \\ \mathrm{T}=42, & \mathrm{~T}=36, & \mathrm{~T}=38, & \mathrm{~T}=54, \\ \mathrm{M}=48, & \mathrm{M}=50, & \mathrm{M}=46, & \mathrm{M}=66, \\ \mathrm{~F}=37 ; & \mathrm{F}=23 ; & \mathrm{F}=32 ; & \mathrm{F}=44 ; \\ \text { Grade } 12: & \mathrm{Grade} 12: & \mathrm{Grade} 12: & \mathrm{Grade} 12: \\ \mathrm{T}=38, & \mathrm{~T}=32, & \mathrm{~T}=33, & \mathrm{~T}=50, \\ \mathrm{M}=42, & \mathrm{M}=44, & \mathrm{M}=42, & \mathrm{M}=62, \\ \mathrm{~F}=32 & \mathrm{~F}=17 & \mathrm{~F}=25 & \mathrm{~F}=38 \\ & \mathrm{M}=30, & \mathrm{M}=38, & \mathrm{M}=68, \\ & \mathrm{~F}=9 & \mathrm{~F}=38 & \mathrm{~F}=47 \\ & & & \end{array}$

Note. $\mathrm{T}=$ total sample; $\mathrm{M}=$ males $; \mathrm{F}=$ females $; \mathrm{PE}=$ physical education. 
Table 2 provides summaries of the methods and results of four studies in which the published data could be "reduced" to estimates of daily time spent in moderate or vigorous physical activity. Although these studies were undertaken in four different countries and although the methods varied markedly across the studies, the results of all the studies point to the general conclusion that, on average, adolescents engage in physical activity of at least moderate intensity for $0.5-1.5$ hours per day. Participation in vigorous physical activity was specifically examined in two of the four studies, and mean participation time tended to fall in the range of 0.4 to 0.7 hours per day.

The results of these small group studies constitute an interesting and useful frame of reference interpreting the findings of population surveys like the NCYFS-I. The global conclusion of NCYFS-I was that U.S. adolescents participate in about 100 minutes ( 1.6 hours) of physical activity per day, a value that is about $67 \%$ greater than the approximate median time in moderate to vigorous activity (1.0 hour) as observed in the small group studies. On the one hand, it is encouraging that the various studies, despite using markedly different methodologies, yielded results that are in the same general range. On the other hand, it appears likely that survey instruments like that used in NCYFS-I provide an overestimate of true physical activity time. This is not surprising, and therefore, the balanced conclusion would be that, on average, adolescents tend to engage in moderate to vigorous physical activity for about one hour per day.

\section{Relationship of Physical Activity to Age and Gender}

Because the methods used in the various descriptive studies of physical activity in adolescents have been so varied, comparison of the estimates of absolute activity levels across these studies is difficult. However, most of these studies have reported activity observations by age and gender categories. Therefore, it is possible to examine age and gender-related trends within and across the various studies.

Sallis (22) performed such an analysis, examining most of the studies cited above. While there is a considerable level of interstudy variability, it has been consistently observed that males are more active than females and that activity levels tend to decline with increasing age during childhood and adolescence. Sallis' global conclusion was that males are about 15 to $25 \%$ more active than females and that, during the school-age years, activity levels decline at a rate of about $2.7 \%$ per year in males and $7.4 \%$ per year in females. Data from YRBS were not included in Sallis' analysis, but they are consistent with his conclusion (see Table 1).

\section{Physical Activity Patterns in Adolescents}

There have been only a few studies that report the actual types of physical activities in which adolescents participate. In general, bicycling, swimming, and ball sports are the predominate physical activities reported $(10,13,23)$. The types of physical activity and level of intensity do show some variability across age, gender, and setting (in or out of school). 
Table 2 Results of Small Group Studies of Physical Activity in Adolescents

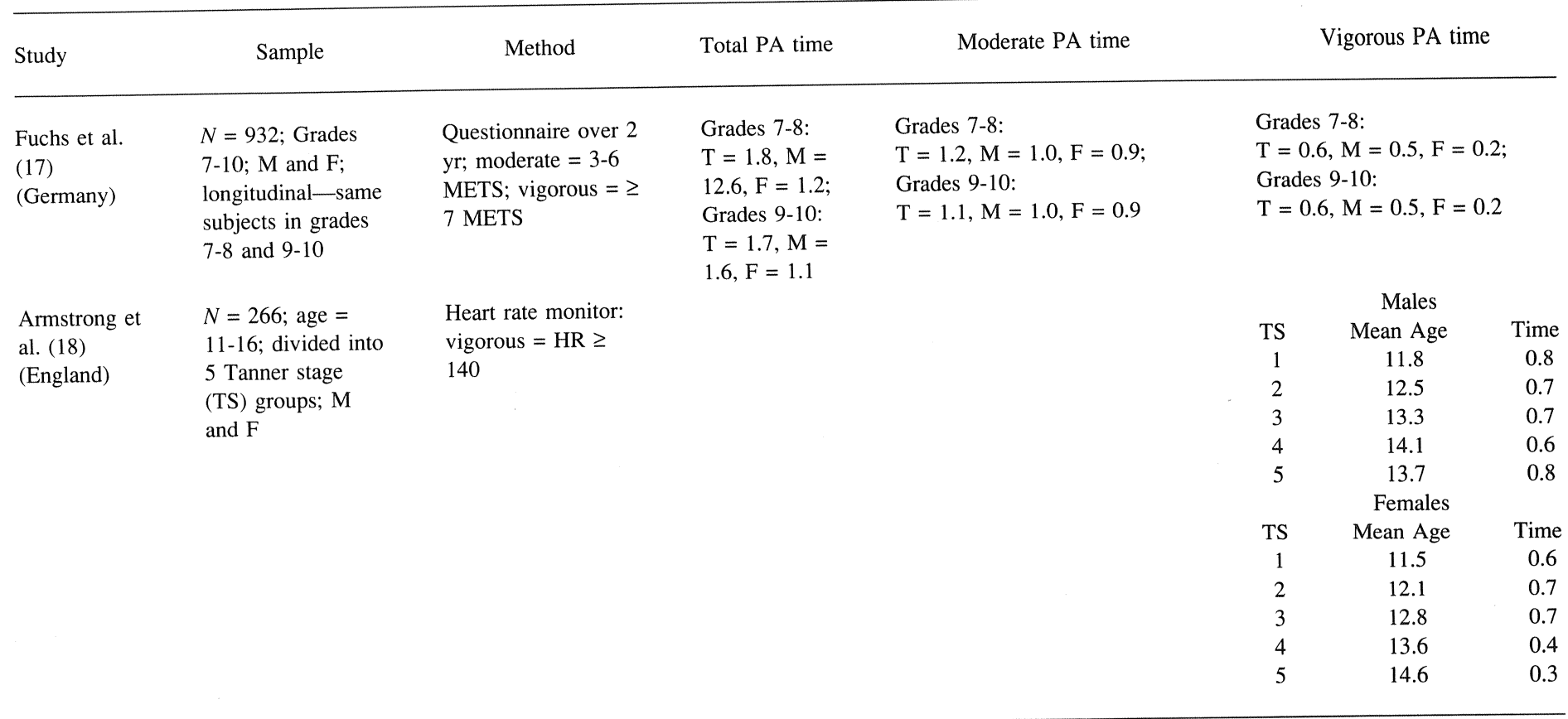


Table 2 (continued)

Study Sample Method Total PA time Moderate PA time

\begin{tabular}{|c|c|c|c|c|c|c|c|c|}
\hline $\begin{array}{l}\text { Sallis et al. } \\
\text { (19) } \\
\text { (U.S.A.) }\end{array}$ & $\begin{array}{l}N=102 ; \text { Grade } 5 \\
8,11 ; \mathrm{M} \text { and } \mathrm{F}\end{array}$ & $\begin{array}{l}\text { Questionnaire; heart } \\
\text { rate monitor: } \\
\text { moderate }=H R \geq \\
120 ; \text { vigorous }=H R \\
\geq 140\end{array}$ & \multicolumn{3}{|c|}{$\begin{array}{l}\text { Grade } 8: \mathrm{M}=0.3, \mathrm{~F}=0.2 \\
\text { Grade } 11: \mathrm{M}=0.8, \mathrm{~F}=0.3 \\
\mathrm{HR} \geq 120 \\
\text { Grade } 8: \mathrm{M}=1.1, \mathrm{~F}=1.6 \\
\text { Grade } 11: \mathrm{M}=1.4, \mathrm{~F}=0.9\end{array}$} & \multicolumn{3}{|c|}{$\begin{array}{l}\text { Grade } 8: M=0.6, F=0.4 \\
\text { Grade } 11: M=0.9, F=0.5 \\
\text { HR } \geq 140 \\
\text { Grade } 8: M=0.5, F=0.5 \\
\text { Grade } 11: M=0.7, F=0.3\end{array}$} \\
\hline \multirow{8}{*}{$\begin{array}{l}\text { Verschuur \& } \\
\text { Kemper (21) } \\
\text { (Netherlands) }\end{array}$} & \multirow{8}{*}{$\begin{array}{l}\text { Age }=12-18 ; N= \\
233 ; \mathrm{M} \text { and } \mathrm{F} ; \\
\text { longitudinal-same } \\
\text { subjects followed } \\
\text { for } 4 \text { years }\end{array}$} & \multirow{8}{*}{$\begin{array}{l}\text { Heart rate monitor: } \\
\text { moderate }=\mathrm{HR} \geq \\
\mathrm{HR} \text { at } 50 \% \mathrm{VO}_{2} \max \\
\text { vigorous }=\mathrm{HR}^{2} \geq \\
\mathrm{HR} \text { at } 75 \% \mathrm{VO}_{2} \max \end{array}$} & \multicolumn{3}{|c|}{$50 \%$ of maximal oxygen uptake } & \multicolumn{3}{|c|}{$75 \%$ of maximal oxygen uptake } \\
\hline & & & Age & M & $\mathrm{F}$ & Age & M & $\mathrm{F}$ \\
\hline & & & $12-13$ & 1.3 & 1.2 & $12-13$ & 0.2 & 0.2 \\
\hline & & & $13-14$ & 1.3 & 1.0 & & & \\
\hline & & & $14-15$ & 1.3 & 1.1 & & & \\
\hline & & & $15-16$ & 1.0 & 0.9 & & & \\
\hline & & & $16-17$ & 0.7 & 1.0 & & & \\
\hline & & & $17-18$ & 0.5 & 0.8 & $17-18$ & 0.1 & 0.1 \\
\hline
\end{tabular}

Note. $\mathrm{T}=$ total; $\mathrm{M}=$ male; $\mathrm{F}=$ female. Time is measured in hours per day. 


\section{School Settings}

Physical education classes represent an important potential source of physical activity. The NCYFS-I reported in 1985 that $80 \%$ of 5 th-12th graders were enrolled in physical education classes. The percentage of enrollment in PE declined over age groups from a high of $97 \%$ in 5 th and 6 th grade to $50 \%$ in 11 th and 12th grade. The average number of sessions per week was 3.6, and the average amount of activity time spent in physical education was 2 hours 21 average amount of activity time spente
minutes. Only $36 \%$ of all 5 th-12th graders were reported to participate in physical
education daily. Basketball, calisthenics/exercises, volleyball, baseball/softball, and jogging were the top five physical activities done by adolescents within the school setting. The relative predominance of each activity varied across gender and age group (13).

An important issue regarding physical education classes revolves around the actual content of the physical education classes, specifically, the amount of time students are actually engaged in moderate to vigorous activity during their PE classes. Parcel et al. (14) studied time allotted for various activities during was spent in class organization/management, $27.5 \%$ playing $13.5 \%$ in skills practice, and only $6.1 \%$ in aerobic activities. than during the physical education class.

The NCYFS-I also examined the percentage of physical education curriculum devoted to "lifetime physical activities." These were defined as activities that may be "readily carried into adulthood because they generally need only one or two people" (10, p. 46). They noted that although there was an upward trend across age groups, only $48 \%$ of the physical education class curriculum was devoted to participation in lifetime physical activities.

More recent estimates of participation in school physical education have been reported as part of the CDC's Youth Risk Behavior Surveillance Systems (11). The percentage of 9th-12th graders reporting enrollment in physical education classes varied across state and local surveys from 24-96\% (median $=52 \%$ ).

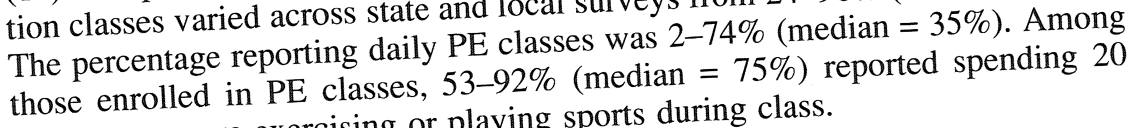
minutes or more exercising or playing sports during class.

\section{Nonschool Settings}

Studies have demonstrated that the majority of physical activity in the adolescent population occurs outside of school $(13,23)$. Although there is a downward trend across adolescence, the majority spend more than 3 hours per week in leisure time activities outside of school $(10,17,23)$. The NCYFS reported that the top five activities for boys were bicycling, basketball, football, baseball/softball, and swimming. The top five activities for girls were swimming, bicycling, dancing, roller-skating, and walking. Sixty-three percent of the activities adosits is comparticipated in outside of school fit the classification lifetime activities. This is compared to $48 \%$ participation rate in lifetime activities within PE classes. Girls were found to spend more time participating in lifetime activities than boys did (71\% vs. $56 \% ; 13)$. 
Major sites for activities included parks, community centers, churches, local team sports, and private clubs/organizations. Nearly 50\% of the NCYFS-I population utilized one or more community organizations as sources of activity. Participation in clubs/organizations appears to decrease with increasing age.

\section{Seasonal Variation}

There is a variation in the amount of activity according to time of year. Both the NCYFS-I and the Canada Fitness Survey showed a marked increase during the summer months. This has important implications both for research methodology and for policy planning aimed at physical activity promotion.

\section{TV Watching}

When discussing the physical activity pattern of adolescents, it is interesting to consider their pattern of physical inactivity. Television viewing represents a major leisure-time activity and source of physical inactivity. According to an A.C. Nielsen report (24), the average 10- to 17 -year-old spends $21 \mathrm{hr} /$ week or $3 \mathrm{hr}$ / day watching television. Two cross-sectional Canadian surveys $(23,25)$ and two studies on smaller groups of U.S. adolescents $(26,27)$ have reported average values in the range of 2-3 hours of TV viewing per day.

There have been only a few studies that examined the relationship between the amount of television viewing and physical activity in the adolescent age range. relationships-sectional surveys done in Canada $(23,25)$ failed to demonstrate a done by Tucker (27), adours of TV viewing and physical activity. In the study were more physically fit and males classified as light viewers ( $<2 \mathrm{hr}$ per day) $(2-4 \mathrm{hr})$ or heavy $(>4 \mathrm{hr}) \mathrm{TV}$ viewing active than those in either the moderate group of adolescent females at viewing groups. Robinson et al. (26) assessed a but significant negative association different points in time. They found a weak of baseline activity, but no significanteen hours of TV viewing and the measure change in level of physical activity ove relationship between TV viewing and results of studies to date have been over time in the longitudinal analyses. The requires further study. cents consumes a major portion demonstrate that television viewing by adolesto note that the studies did not of their leisure time. However, it is important and computer games. It appears into account the time spent playing video leisure-time activities would enical to assume that the sum of these passive time physical activity. Considering on time available to participate in leisureplace outside of school when televis the majority of physical activity takes relationship between the two relevision viewing is an alternative option, the

\section{Attainment of Recommended Physical Activity Guidelines}

An expert panel has recommended that adolescents meet the following two 
1. All adolescents should be physically active daily, or nearly every day, as part of play, games, sports, work, transportation, recreation, physical education, or planned exercise in the context of family, school, and community activities.

2. Adolescents should engage in three or more sessions per week of activities that last 20 min or more at a time and that require moderate to vigorous levels of exercise exertion.

In this section of the paper, an estimate will be made of the percentages of U.S. adolescents who meet each of these two guidelines.

\section{Daily Physical Activity}

In describing and operationalizing the first guideline cited above, Healthy People 2000 (4) Objective 1.3 could be applied. This standard will be used in estimating the percentage of adolescents who meet Guideline 1.

As was noted previously, the results of NCYFS-I (when cross-referenced to a number of small group studies) led to the conclusion that the average adolescent engages in about one hour of moderate to vigorous physical activity per day. This observation suggests that the majority of adolescents meet Guideline 1 and can be considered reasonably active on a day-to-day basis.

However, it is important to note that, as observed in NCYFS-I, there is considerable interindividual variability in daily physical activity time. The standard deviation for daily physical activity time approximates $50 \%$ of the mean, suggesting that the recommended 30 min of daily activity (which corresponds to one standard deviation below the mean) lies approximately at the 16 th percentile for adolescents as a total group. Therefore, it can be concluded that most, but not all, adolescents meet Guideline 1. Because activity levels tend to be lower in girls than in boys and because activity levels tend to decrease with age, it is apparent that somewhat higher percentages of girls and older adolescents fail to meet Guideline 1.

\section{Sessions of Moderate to Vigorous Physical Activity}

The results of YRBS constitute the best available evidence concerning the percentage of U.S. adolescents who meet Guideline 2. As presented in Table 1, YRBS indicates that, depending on age and gender, $38-70 \%$ of adolescents report participating in moderate and/or vigorous physical activity sessions three or more days per week. The percentages of youth meeting this standard are consistently higher for males $(62-70 \%)$ than for females $(38-51 \%)$. The percentages of youth meeting the standard decline steadily from $60 \%$ in 9 th graders to $50 \%$ in 12 th graders. Overall, these data indicate that only slightly over one-half of American adolescents meet Guideline 2.

\section{Summary}

A current best estimate is that, on average, adolescents spend about one hour per day in moderate-to-vigorous physical activity. Hence, most adolescents (probably 
over $80 \%$ ) meet Guideline 1, which calls for participation in physical activity for $30 \mathrm{~min}$ or more on most days. A much smaller percentage of adolescents meet Guideline 2, which recommends participation in three or more 20-min sessions of moderate to vigorous physical activity sessions per week. Though the percentage of adolescents meeting this recommendation varies with age and gender, about $50 \%$ of the overall population meets this guideline.

Males are more active than females, in part because of their more frequent participation in vigorous activities and sports. Physical activity shows a downward trend during adolescence, and this trend is more marked in females than in males. Most of the typical adolescent's physical activity is obtained outside of school. Current levels of enrollment in physical education and participation in vigorous physical activity in physical education do not meet the standards set by Healthy People 2000 (4).

It can be concluded that, by comparison with adults, adolescents tend to be quite physically active. However, many adolescents report little participation in structured exercise, and age trends indicate that many adolescents are at risk of becoming sedentary adults.

\section{References}

1. Powell, K.E., C.J. Caspersen, J.P. Koplan, and E.S. Ford. Physical activity and chronic disease. Am. J. Clin. Nutr. 49:999-1006, 1989.

2. Caspersen, C.J., G.M. Christenson, and R.A. Pollard. Status of the 1990 physical fitness and exercise objectives: Evidence from NHIS 1985. Pub. Health Rep. 101:587592, 1986.

3. McGinnis, J.M. The public health burden of a sedentary lifestyle. Med. Sci. Sports Exerc. 24(Suppl.):S196-S200, 1992.

4. Public Health Service. Healthy People 2000: National Health Promotion and Disease Prevention Objectives (DHHS Publication No. PHS 91-50212). Washington, DC: U.S. Department of Health and Human Services, 1990.

5. Baranowski, T., C. Bouchard, O. Bar-Or, T. Bricker, G. Heath, S.Y.S. Kim, R. Malina, E. Obarzanek, R. Pate, W.B. Strong, T. Benedict, and R. Washington. Assessment, prevalence, and cardiovascular benefits of physical activity and fitness. Med. Sci. Sports Exerc. 24(Suppl.):S237-S247, 1992.

6. Simons-Morton, B.G., N.M. O'Hara, D.G. Simons-Morton, and G.S. Parcel. Children and fitness: A public health perspective. Res. Quar. Exerc. Sport 58:295-302, 1987.

7. Sallis, J.F., and T.L. McKenzie. Physical education's role in public health. Res. Quar. Exerc. Sport 62:124-137, 1991.

8. Caspersen, C.J., K.E. Powell, and G.M. Christensen. Physical activity, exercise, and physical fitness: Definitions and distinctions for health-related research. Pub. Health Rep. 100:126-131, 1985.

9. Sallis, J.F. Self-report measures of children's physical activity. J. School Health 61:215-219, 1991.

10. Ross, J.G., and G.G. Gilbert. The national children and youth fitness study: A summary of findings. J. Phys. Educ. Rec. Dance 56(1):45-50, 1985.

11. Centers for Disease Control. Vigorous physical activity among high school students. MMWR 41:91-94, 1992.

12. Freedson, P.S. Electronic motion sensors and heart rate as measures of physical activity in children. J. School Health 61:2220-2223, 1991. 
13. Ross, J.G., C.O. Dotson, G.G. Gilbert, and S.J. Katz. After physical education: Physical activity outside of school physical education programs. J. Phys. Educ Rec. Dance 56(1):77-81, 1985.

14. Parcel, G.S., B.G. Simons-Morton, N.M. O’Hara, T. Baranowski, L.J. Kolbe, and D.E. Bee. School promotion of healthful diet and exercise behaviors: An integration of organizational change and social learning theory interventions. J. School Health 57:150-156, 1987.

15. Sports Council and Health Education Authority. Allied Dunbar National Fitness Survey. London: Belmont Press, 1993.

16. Stephens, T. Leisure time physical activity. In: Canada's Health Promotion Survey 1990: Technical Report, T. Stephens and F.D. Graham (Eds.). Ottawa, ON: Health and Welfare Canada, 1993, pp. 139-150.

17. Fuchs, R., K.E. Powell, N.K. Semmer, J.H. Dwyer, P. Lippert, and H. Hoffmeister. Patterns of physical activity among German adolescents: The Berlin-Bremen study. Prev. Med. 17:746-763, 1988.

18. Armstong, N., J. Balding, P. Gentle, and B. Kirby. Patterns of physical activity among 11 to 16 year old British children. Br. Med. J. 30:203-205, 1990.

19. Sallis, J.F., M.J. Buono, J.J. Roby, F.G. Micale, and J. Nelson. 7-day recall and other physical activity self-reports in children and adolescents. Med. Sci. Sport Exerc. 25:99108, 1993.

20. Sunnegardh, J., L.E. Brattebny, S. Sjolin, U. Hagman, and A. Hoffstedt. The relation between physical activity and energy intake of 8- and 13-year-old children in Sweden. In: Children and Exercise XI, R.A. Binkhorst, H.C.G. Kemper, and W.H.M. Saris (Eds.). Champaign, IL: Human Kinetics, 1985, pp. 183-193.

21. Verschuur, R., and H.C.G. Kemper. The pattern of daily physical activity. In: Growth, Health, and Fitness of Teenagers, H.C.G. Kemper (Ed.). New York: Karger, 1985, pp. 169-186.

22. Sallis, J.F. Epidemiology of physical activity and fitness in children and adolescents. Crit. Rev. Food Sci. Nutr. 33:403-408, 1993.

23. Stephens, T., and C.I. Craig. The Well-Being of Canadians: Highlights of the Campbells' Survey. Ottawa: Canadian Fitness and Lifestyle Research Institute.

24. A.C. Nielsen Company. 1990 Nielsen Report on Television. New York: Author, 1990.

25. Shephard, R.J. Fitness of a nation: Lessons from the Canada fitness survey. In: Medicine and Sport Science, M. Hebbelinck and R.J. Shephard (Eds.). New York: Karger, 1986.

26. Robinson, T.N., L.D. Hammer, J.D. Killen, H.C. Kraemer, D.M. Wilson, C. Hayward, and C.B. Taylor. Does television viewing increase obesity and reduce physical activity cross-sectional and longitudinal analysis among adolescent girls. Pediatr. 91:273280, 1993.

27. Tucker, L.A. The relationship of television viewing to physical fitness and obesity. Adolescence 21:797-806, 1986.

28. Sallis, J.F., and K. Patrick. Physical activity guidelines for adolescents: Consensus statement. Ped. Exerc. Sci. 6:302-314, 1994. 